\title{
Letter
}

\section{ITGAV polymorphism and disease susceptibility in a Japanese rheumatoid arthritis population}

\author{
Noriko likuni, Shu Kobayashi, Katsunori lkari, Taisuke Tomatsu, Masako Hara, Hisashi Yamanaka, \\ Naoyuki Kamatani and Shigeki Momohara
}

Institute of Rheumatology, Tokyo Women's Medical University, 10-22 Kawada, Tokyo, 162-0054 Japan

Corresponding author: Katsunori lkari, kikari@ior.twmu.ac.jp

Published: 31 October 2007

This article is online at http://arthritis-research.com/content/9/5/405

Arthritis Research \& Therapy 2007, 9:405 (doi:10.1186/ar2303)

(c) 2007 BioMed Central Ltd

See related research article by Jacq et al., http://arthritis-research.com/content/9/4/R63, and related editorial by Ahnert and Kirsten, http://arthritis-research.com/content/9/5/108

A research article by Jacq and colleagues [1], recently published in this journal, reported an association between rheumatoid arthritis (RA) and the rs3738919-C allele in the ITGAV gene, which encodes the $\alpha_{v}$ subunit of the integrin $\alpha_{v} \beta_{3}$, in a European Caucasian population.

One feature of the pathophysiology of RA is the hyperangiogenesis observed in the synovial tissue and, along with excess macrophages and $\mathrm{T}$ lymphocytes, $\alpha_{v} \beta_{3}$ ligands are also abundant in synovial fluid [2]. As a key player in angiogenesis [3], it has been suggested that ITGAV may be a RA susceptibility gene. The linkage study also supports this view because the 2 q31 region containing ITGAV exhibited linkage in a dense genome scan [4].

Although the European association study by Jacq and colleagues [1] indicated ITGAV to be a new minor RA susceptibility gene, a replication study conducted in a population of different ethnicity is helpful in exploring whether the association is caused by a common variance through various ethnic groups. We therefore undertook a large population-based study to investigate the association between ITGAV and RA in a Japanese population.
DNA samples were obtained from 1,504 Japanese RA patients and 449 population control individuals [5]. Genotypes were determined using the TaqMan method, in accordance with the manufacturer's instructions (Applied Biosystems, Tokyo, Japan). Table 1 shows the genotype distributions and allelic frequencies of patients and control individuals. Unlike the European population, the rs3738919C allele was more frequent in control individuals in our Japanese population, and no significant differences were observed in allele frequencies for Japanese RA patients and control individuals (0.908 and 0.922, respectively).

There are several factors that must be accounted for when a study fails to corroborate a previously identified association. One of these is an ethnicity-specific effect. Ethnic differences can result in differences in allele frequencies, and the genetic background of the disease itself may vary between ethnic groups. Another issue that must be considered is that, usually, negative association studies of a target gene outside the HLA region lack sufficient power to detect the genetic effect because the disease-associated genes outside the region may be associated with limited relative risk for disease susceptibility. While considering the odds ratio of Jacq et

Table 1

Distribution of ITGAV rs3738919 genotypes in Japanese rheumatoid arthritis patients and control individuals

\begin{tabular}{|c|c|c|c|c|c|c|c|c|c|}
\hline & \multicolumn{5}{|c|}{ Genotype } & \multicolumn{2}{|c|}{$C$ versus $A$} & \multicolumn{2}{|c|}{$C C+C A$ vs. $A A$} \\
\hline & $\mathrm{CC}$ & $\mathrm{CA}$ & $\mathrm{AA}$ & Total & MAF & OR (95\% Cl) & $P^{a}$ & OR (95\% Cl) & $P a$ \\
\hline Patients & 1,221 & 259 & 8 & 1,488 & 0.092 & $1.20(0.91$ to 1.60$)$ & 0.23 & 0.60 (0.16 to 2.72$)$ & 0.49 \\
\hline Controls & 380 & 62 & 4 & 446 & 0.078 & & & & \\
\hline
\end{tabular}

The distribution of the genotypes followed the Hardy-Weinberg equilibrium for both groups. a $P$ values were obtained using Fisher's exact test $(\mathrm{R}$ version 2.4.1). $\mathrm{Cl}$, confidence interval; $M A F$, minor allele frequency; $O R$, odds ratio. 
al.'s study [1], our study was designed to have sufficient power to detect the effect of the ITGAV gene $>0.96$; number of cases $=1504$, number of controls $=449$, OR in the original French study [1] $=1.94$, frequency of rs3738919-A allele in the controls $=0.078$, significance level $=0.05$ ). However, when the odds ratio is under 1.67, the power is limited to below 0.8 , and this may represent a study limitation.

Despite its association with RA in Caucasian populations, an association of the ITGAV gene with RA patients in the Japanese was not observed. Further studies in other ethnic groups are necessary to draw definite conclusions.

\section{Competing interests}

The authors declare that they have no competing interests.

\section{References}

1. Jacq $L$, Garnier $S$, Dieude $P$, Michou L, Pierlot $C$, Migliorini $P$, Balsa A, Westhovens R, Barrera $\mathrm{P}$, Alves $\mathrm{H}$, et al:: The ITGAV rs3738919-C allele is associated with rheumatoid arthritis in the European Caucasian population: a family-based study. Arthritis Res Ther 2007, 9:R63.

2. Friedlander M, Brooks PC, Shaffer RW, Kincaid CM, Varner JA, Cheresh DA: Definition of two angiogenic pathways by distinct alpha v integrins. Science 1995, 270:1500-1502.

3. Eliceiri BP, Cheresh DA: The role of alphav integrins during angiogenesis: insights into potential mechanisms of action and clinical development. J Clin Invest 1999, 103:1227-1230.

4. Osorio YFJ, Bukulmez H, Petit-Teixeira E, Michou L, Pierlot C, Cailleau-Moindrault S, Lemaire I, Lasbleiz S, Alibert O, Quillet $P$, et al:: Dense genome-wide linkage analysis of rheumatoid arthritis, including covariates. Arthritis Rheum 2004, 50:27572765.

5. Iwamoto T, Ikari K, Inoue E, Toyama $Y$, Hara M, Yamanaka H, Tomatsu T, Momohara S, Kamatani N: Failure to confirm association between PDCD1 polymorphisms and rheumatoid arthritis in a Japanese population. J Hum Genet 2007, 52:557-560. 